\title{
Proteus mirabilis biofilm - Qualitative and quantitative colorimetric methods-based evaluation
}

\author{
Joanna Kwiecinska-Piróg, Tomasz Bogiel, Krzysztof Skowron, Ewa Wieckowska, \\ Eugenia Gospodarek
}

\begin{abstract}
Department of Microbiology, Faculty of Pharmacy, Ludwik Rydygier Collegium Medicum, Nicolaus Copernicus University in Torun, Bydgoszcz, Poland.
\end{abstract}

Submitted: August 13, 2013; Approved: April 17, 2014.

\begin{abstract}
Proteus mirabilis strains ability to form biofilm is a current topic of a number of research worldwide. In this study the biofilm formation of $P$. mirabilis strains derived from urine of the catheterized and non-catheterized patients has been investigated. A total number of 39 P. mirabilis strains isolated from the urine samples of the patients of dr Antoni Jurasz University Hospital No. 1 in Bydgoszcz clinics between 2011 and 2012 was used. Biofilm formation was evaluated using two independent quantitative and qualitative methods with TTC (2,3,5-triphenyl-tetrazolium chloride) and CV (crystal violet) application. The obtained results confirmed biofilm formation by all the examined strains, except quantitative method with TTC, in which $7.7 \%$ of the strains did not have this ability. It was shown that $P$. mirabilis rods have the ability to form biofilm on the surfaces of both biomaterials applied, polystyrene and polyvinyl chloride (Nelaton catheters). The differences in ability to form biofilm observed between $P$. mirabilis strains derived from the urine of the catheterized and non-catheterized patients were not statistically significant.
\end{abstract}

Key words: Proteus mirabilis, biofilm, colorimetric methods.

\section{Introduction}

Proteus spp. rods are widely disseminated in the environment. They live in soil, water and organisms of mammals, including humans. They play important role in the natural environment, decomposing organic material of the animal origin (Drzewiecka and Sidorczyk, 2005; Hola et al., 2012; Jacobsen and Shirtliff, 2011; Liu, 2011; Rózalski et al., 2007). The most commonly isolated representative of this genus, $P$. mirabilis, is the cause of the nosocomial infection butcan be also found in the digestive tract of dogs, cows and birds (Liu, 2011; Rózalski et al., 2007; Szewczyk, 2006).

Proteus spp. rods are Gram-negative bacteria (1-3x 0.4-0.8 $\mu \mathrm{m})$, motile at the temperature of $36^{\circ} \mathrm{C}$. They can be cultured in both, aerobic and anaerobic condition, with fermentation metabolism type. One of the main Proteus spp. strains properties is dimorphism - depending on the current environment conditions they display physiologic and morphologic changes (Jones et al., 2007; Mobley and Belas, 1995). This process is initiated by the bacteria contact with the solid surface and refers for example to morphology type change from shorter "swimmer cells" to elongated "swarmer cells".

Proteus spp. rods are typical opportunistic pathogens, relatively infectious and contribute to the infections mostly in immunocompromised patients. Those infections are usually long-term and difficult to cure (Drzewiecka and Sidorczyk, 2005).

Urinary tract infections (UTI) (Rózalski et al., 2007) belong to one of the main Proteus spp. rods infections manifestation. They can be found usually amongst patients with anatomical and/or physiological malformations in the urinary tract but can also afflict patients with long-term or repeating catheterization or after surgical procedures (Drzewiecka and Sidorczyk, 2005). Proteus spp. rods may also contribute to respiratory tract and wounds infection, including burn ones, but also to other infections, e.g. diges-

Send correspondence to K. Skowron. Department of Microbiology, Faculty of Pharmacy, Nicolaus Copernicus University in Torun, Ludwik Rydygier Collegium Medicum in Bydgoszcz, 9 Maria Sklodowska-Curie Street, 85-094 Bydgoszcz, Poland. E-mail: skowron238@wp.pl. 
tive tract, throat, bones, eyes, ears, nose, skin infection and arthritis or meningitis. Proteus spp. rods have been also isolated from the blood cultures. Over $60 \%$ of the infections caused by Proteus spp. afflict hospitalized patients, with $5 \%$ cases of the nosocomial bacteraemia linked with $P$. mirabilis (Drzewiecka and Sidorczyk, 2005; Rózalski et al., 2007; Dubiel et al., 2011).

An important virulence factor of these bacteria is the ability to form biofilm. In which different fractions of microorganism play specialized roles. The biofilm structure preserves bacteria from unfavourable influence of the environment conditions and facilitates distribution of the nutritional agents (Kolwzan, 2011). Biofilm protects bacteria from immune system response of the host (hinders phagocytosis, chemotaxis, opsonisation), decreases antibiotics and antibodies penetration (Bartoszewicz and Rygiel, 2006).

Biofilm forming process consists of initial reversible bacterial adhesion to a surface, irreversible attachment, microcolony formation, maturation and detachment (Kolwzan, 2011; O'Toole et al., 2000). The mature biofilm is multilayer with free bacteria on the surface that can come off the biofilm structure and move in order to find favourable environment conditions (Rózalski et al., 2007).

The typical property of the biofilm-submerged bacteria is approximately 1000 -fold increased resistance to a majority of the antimicrobials, when compared to planktonic counterparts. Biofilm formed on the abiotic surfaces is believed to be major cause of $65 \%$ of the nosocomial infections (Czaczyk and Myszka, 2007).

$P$. mirabilis rods display ability to form biofilm in different environments, including abiotic (e.g. polystyrene, glass, latex, silicone) and biological surfaces. It was also confirmed that the biofilm can consist of single-species or multi-genera bacteria community (Jacobsen and Shirtliff, 2011).

$P$. mirabilis rods develop two types of biofilm, depending on the culture medium. In Luria-Bertanii bullion and human urine biofilm has a typical fungal biofilm-like structure with nutritional channels while in the artificial urine it is formed as a flat layer with swarmer cells" population protruding the structure surface (Jones et al., 2007).

The most widely investigated $P$. mirabilis biofilms are those in the urinary tract, particularly on the catheters surface. The important issues are the crystalized biofilms that lead to catheter incrustation and obstruction. Two main types of crystals may be found inside them: struvite (magnesium ammonium phosphate) and apatite (hydroxyl calcium phosphate). They appear in the urinary tract biofilms and block the urine flow (Jacobsen and Shirtliff, 2011). It may cause urine blockage in the bladder, bacteriuria episodes, fever, sepsis and shock (Jones et al., 2007).

The aim of this work was the evaluation and comparison of the usefulness of selected qualitative and quantitative colorimetric methods to estimate of $P$. mirabilis biofilm forming abilities.

\section{Materials and Methods}

\section{Strains origin and identification}

Thirty nine $P$. mirabilis strains were used in this study. They were isolated from urine derived from the patients treated between 2011 and 2012 in the clinics of the Dr Antoni Jurasz University Hospital No. 1 in Bydgoszcz. Nineteen (48.7\%) strains were isolated from urine collected from catheterized while $20(51.3 \%)$ strains from the urine of non-catheterized patients. The majority of the $P$. mirabilis strains was derived from the specimens of the patients treated in the Rehabilitation $(9 ; 23.0 \%)$ and General and Endocrinology Surgery 5 (12.8\%) Clinics (Figure 1).

Identification of the strains was conducted using one of the following tests: API 20E/ID32E (BioMérieux) or VITEK GN cards (BioMérieux) according to the manufacturers' recommendations. Strains were stored in a brainheart infusion (Becton Dickinson) with 20.0\% glycerol (POCH) at $-70{ }^{\circ} \mathrm{C}$.

\section{Quantitative evaluation of biofilm formation}

Biofilm was formed in the wells of the 96-wells polystyrene titer plates and investigated with two quantitative methods. Absorbance values of two dyes: crystal violet $(\mathrm{CV}$; POCH) and formazan (product of the 2,3,5-triphenyl-tetrazolium chloride dissolution, TTC; POCH) were investigated at the same time. Staphylococcus aureus ATCC $6538 \mathrm{P}$ (very strongly biofilm forming strain) and $E$. coli ATCC 35218 (weakly biofilm forming strain) reference strains served as controls.

The examined strains of $P$. mirabilis were plated on the cysteine lactose electrolyte deficient medium (CLED; Becton Dickinson) while the reference strains on $5.0 \%$ sheep blood agar (Becton Dickinson). Strains were cultured at $37^{\circ} \mathrm{C}$ for $18 \mathrm{~h}$. Next, the single colonies were inoculated into tryptic soy bullion (Bio-Rad). After $18 \mathrm{~h}$ at $37^{\circ} \mathrm{C}$, each culture was centrifuged for $15 \mathrm{~min}$ at $4000 \mathrm{rpm}$, and the supernatant was discarded. The remaining pellet was rinsed with $3 \mathrm{~mL}$ of phosphate buffered saline solution $(\mathrm{pH}=7.2)$ (PBS; POCH). Next, the bacterial suspension was centrifuged at $4000 \mathrm{rpm}$ for $10 \mathrm{~min}$ and the pellet was used to make the suspension of 0.5 MacFarland turbidity in TSB. Then, $20 \mu \mathrm{L}$ of every suspension was placed in the wells of polystyrene 96-well plate, in four repetitions each. The wells were filled with $180 \mu \mathrm{L}$ of a sterile TSB medium. A sterility control was made of $200 \mu \mathrm{L}$ TSB medium in at least four repetitions. The culture was incubated in a humid chamber at $37^{\circ} \mathrm{C}$ for $24 \mathrm{~h}$.

\section{CV-based assay}

After 24-incubation, the solutions were removed, the wells rinsed with sterile distilled water and left to dry at $37^{\circ} \mathrm{C}$ for $20 \mathrm{~min}$. Next, $200 \mu \mathrm{L}$ of methanol (POCH) were added to each well. The plates were placed onto a shaker at $400 \mathrm{rpm}$ for $20 \mathrm{~min}$ at room temperature. Then, the metha- 


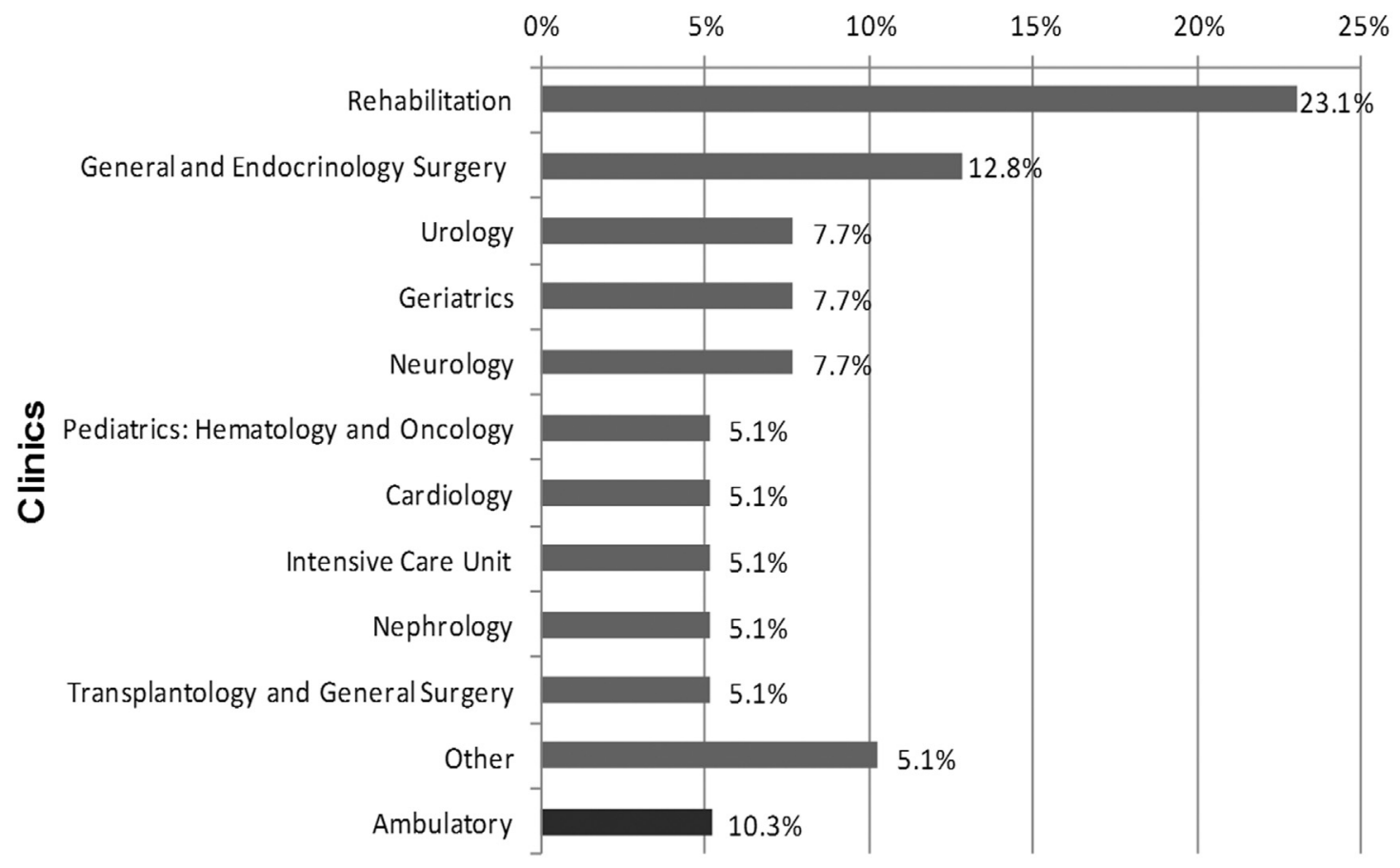

Figure 1 - Origin of the examined P. mirabilis strains $(\mathrm{n}=39)$. Other: Palliative Care Unit, Endocrinology and Diabetology Clinic, Stroke Unit, Rehabilitation in Orthopedics.

nol was removed and the plates left to dry at $37{ }^{\circ} \mathrm{C}$ for $20 \mathrm{~min}$. In the next step, $200 \mu \mathrm{L}$ of $0.1 \% \mathrm{CV}$ were added to each well and the plates were placed on a shaker at $400 \mathrm{rpm}$ for 10 min at room temperature. Next, the $\mathrm{CV}$ was removed by rinsing the wells with water thoroughly until the control wells became colorless. The plates were left for $20 \mathrm{~min}$ at $37^{\circ} \mathrm{C}$ for the water to evaporate. Finally, $200 \mu \mathrm{L}$ of methanol were added to each well and left on a shaker for $5 \mathrm{~min}$ at $400 \mathrm{rpm}$ and room temperature.

\section{TTC-based assay}

After 24-h incubation, the solutions were removed and the wells rinsed tree times with sterile PBS. Next, $100 \mu \mathrm{L}$ of TSB and $100 \mu \mathrm{L}$ of $0.1 \%$ TTC were added to each well. The plates were placed on a shaker at $400 \mathrm{rpm}$ for $5 \mathrm{~min}$ at room temperature. Next, the plates were placed in $37^{\circ} \mathrm{C}$. After 2-h incubation, the TTC was removed and plates were rinsed tree times with sterile PBS. Finally, $200 \mu \mathrm{L}$ of methanol were added to each well and left on a shaker at $400 \mathrm{rpm}$ for $5 \mathrm{~min}$ at room temperature.

\section{Absorbance measurement}

Absorbance (A) read-outs were conducted with a spectrophotometer at the wavelength of 570 and $470 \mathrm{~nm}$ for CV and TTC, respectively using KC4 v3.4 and KC4 Signature programs. To assess biofilm forming for each strain and negative control, the arithmetic mean of absorbance and standard deviation were used. The threshold value of absorbance $(\mathrm{T})$ was proof of the biofilm formation and was defined as the sum of the arithmetic mean of negative control and a triple value of its standard deviation $\left(\mathrm{T}=x_{n c}+3 \delta\right)$ (Table 1).

\section{Qualitative methods for biofilm detection}

Qualitative methods for biofilm detection were applied for biofilm evaluation on the polyvinyl chloride surface of the urinary catheter (Nelaton, Unomedical).

Single colonies of each of the examined strains from the bacteria cultures on CLED and 5.0\% sheep blood medium (control strains) were inoculated into $2 \mathrm{~mL}$ TSB. $1-\mathrm{cm}$ long sterile catheter fragments were added to the suspensions and incubated for $22 \mathrm{~h}$ at $37^{\circ} \mathrm{C}$ for TTC or $24 \mathrm{~h}$ for CV assay.

For the TTC dissolution intensity $20 \mu \mathrm{L}$ of $0.5 \%$ TTC were added to the wells with 22-h cultures and additionally incubated for two hours at $37^{\circ} \mathrm{C}$. Next, the catheter fragments were rinsed three times in PBS and biofilm forma-

Table 1 - P. mirabilis strains biofilm forming intensity criteria with respect to the measured absorbance (A) value.

\begin{tabular}{lc}
\hline Absorbance value & Biofilm intensity \\
\hline $\mathrm{A} \leq \mathrm{T}$ & Lack \\
$\mathrm{T}<\mathrm{A} \leq 2 \mathrm{~T}$ & Weak \\
$2 \mathrm{~T}<\mathrm{A} \leq 4 \mathrm{~T}$ & Moderate \\
$4 \mathrm{~T}<\mathrm{A} \leq 8 \mathrm{~T}$ & Strong \\
$>8 \mathrm{~T}$ & Very strong \\
\hline
\end{tabular}


tion was estimated visually in terms of the obtained colour intensity (Figure 2A).

For the CV assay the biomaterial fragments, previously incubated and covered with 24 -h biofilm, were moved to Petri dishes filled with CV. After 5 min of staining, biomaterial were washed with water and visually evaluated in terms of biofilm forming intensity (Figure 2B).

\section{Statistical analysis}

Statistical analysis was conducted using the StatSoft Inc. (2011) STATISTICA 10.0 program (data analysis software system) and Microsoft Office Excel 2007 with differences at $\mathrm{p} \leq 0.05$ considered as statistically significant. The obtained results normality was evaluated with ShapiroWilk test. Non-parametric Wilcoxon test was applied to compare differences obtained for the same strains while the comparison of the differences in the results observed between groups was evaluated with $\mathrm{chi}^{2}$ and $\mathrm{U}$ MannWhitney's tests.

\section{Results}

\section{Quantitative evaluation of biofilm formation}

$\mathrm{CV}$ assay results revealed ability of all of the strains tested to form biofilm, while in the TTC assay - $36(92.3 \%)$ of the strains studied (Table 2). Three of the strains that did not form biofilm while quantitative results interpretation was applied, were confirmed as moderate and strong biofilm producers - $1(2.6 \%)$ and $2(5.1 \%)$, respectively when qualitative evaluation was done.

Higher percentage $(35.9 \%)$ of the strains with the ability to form biofilm very strongly was noted for quantitative interpretation of the TTC assay was applied when compared to the CV assay (2.5\%). The results obtained using CV indicated the highest percentage $(69.0 \%)$ of the $P$. mirabilis strains with ability to form biofilm moderately (Table 2).

Statistically important difference $(\mathrm{p}=0.0003)$ was observed in P. mirabilis biofilm formation intensity evaluated by two independent quantitative methods.

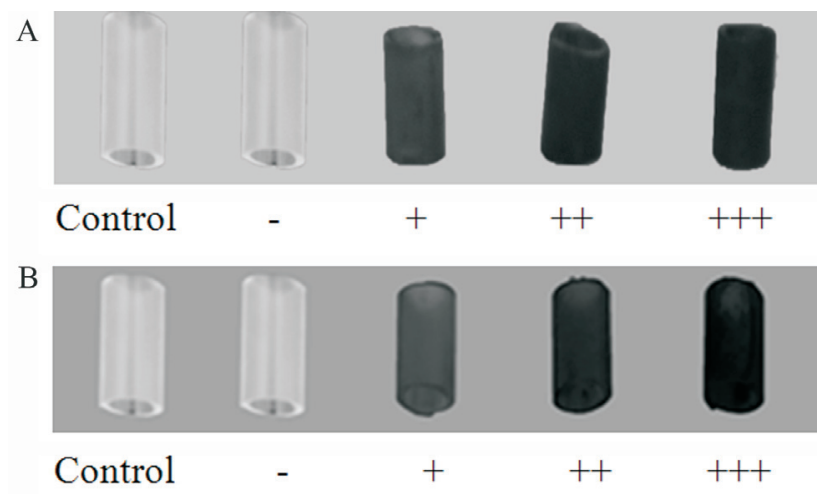

Figure 2 - Criteria of the biofilm formation ability evaluation established for qualitative TTC- (A) and CV-based (B) method.

\section{Qualitative evaluation of biofilm formation}

Applying qualitative methods for interpretation of $P$. mirabilis ability to form biofilm in vitro, all of the examined strains were interpreted as biofilm producers. Higher percentage $(64.1 \%)$ of the strains interpreted as strong biofilm producers was obtained applying TTC method. Using CV assay predominantly, moderate ability to form biofilm was detected (48.7\%). Amongst the strains interpreted as strong biofilm producers using TTC assay, 7 were confirmed as weak biofilm producer when $\mathrm{CV}$ assay was applied (Table 3).

Statistically significant difference $(\mathrm{p}=0.0022)$ was observed in $P$. mirabilis biofilm formation intensity evaluation by two independent qualitative methods.

\section{Relation between the results of the qualitative and quantitative methods applied}

Applying TTC assay only qualitative interpretation revealed the ability to form biofilm by all examined P. mirabilis strains and domination of the isolates with strong biofilm forming ability $(64.1 \%)$ (Table 4$)$. Meanwhile, in the quantitative method $P$. mirabilis strains with very strong biofilm forming ability accounted for $35.9 \%$ of the all tested strains (Table 4).

Table 2 - P. mirabilis strains biofilm forming intensity evaluation with respect to the applied quantitative methods.

\begin{tabular}{|c|c|c|c|c|c|c|}
\hline \multirow[b]{2}{*}{ CV-based assay } & \multicolumn{6}{|c|}{ TTC-based assay } \\
\hline & Total & Lack & Weak & Moderate & Strong & Very strong \\
\hline Total & 39 & 3 & 5 & 7 & 10 & 14 \\
\hline Lack & 0 & 0 & 0 & 0 & 0 & 0 \\
\hline Weak & 3 & 0 & 0 & 1 & 1 & 1 \\
\hline Moderate & 27 & 2 & 5 & 4 & 7 & 9 \\
\hline Strong & 8 & 0 & 0 & 2 & 2 & 4 \\
\hline Very strong & 1 & 1 & 0 & 0 & 0 & 0 \\
\hline
\end{tabular}

CV - crystal violet.

TTC - 2,3,5-triphenyl-tetrazolium chloride. 
Using both evaluation methods types and CV assay, only one $P$. mirabilis strains $(2.5 \%)$ was detected to form biofilm very strongly (Table 5 ) in quantitative estimation. Higher percentage $(69.2 \%)$ of the strains in this case was classified as moderate biofilm producers. Applying qualitative method, moderate ability to form biofilm was detected amongst the highest percentage (48.7\%) of the strains examined (Table 5).

Comparison of the urine-derived $P$. mirabilis strains ability to form biofilm with respect to catheterization of the patients

Regardless of the applied quantitative or qualitative methods for the ability to form biofilm investigation by urine-derived $P$. mirabilis strains isolated from non- and catheterized patients none statistically significant differ- ences were observed ( $p>0.05)$ between patients groups (Figures 3 and 4).

\section{Discussion}

Biofilm formation on the surfaces of material of medical devices is unquestionably critical therapeutic problem of the current medicine. This phenomenon for P. mirabilis is particularly common and linked to clinical complications due to crystalized biofilm type. Urinary tract catheterization facilitates bacteria growth in the favourable conditions of biofilm structure. Because of that, proper detection of bacteria ability to form biofilm seems to be crucial aspect of medical investigation.

Mahdavi et al. (2007) during the evaluation of different nisin concentration on biofilm forming by pathogenic

Table 3 - P. mirabilis strains biofilm forming intensity comparison, evaluated on the polyvinyl chloride surface, with respect to the applied qualitative method.

\begin{tabular}{|c|c|c|c|c|c|}
\hline \multirow[b]{2}{*}{ CV-based assay } & \multicolumn{5}{|c|}{ TTC-based assay } \\
\hline & Total & Lack & Weak & Moderate & Strong \\
\hline Total & 39 & 0 & 2 & 12 & 25 \\
\hline Lack & 0 & 0 & 0 & 0 & 0 \\
\hline Weak & 9 & 0 & 0 & 2 & 7 \\
\hline Moderate & 19 & 0 & 2 & 8 & 9 \\
\hline Strong & 11 & 0 & 0 & 2 & 9 \\
\hline
\end{tabular}

CV - crystal violet.

TTC - 2,3,5-triphenyl-tetrazolium chloride.

Table 4 - $P$. mirabilis strains biofilm forming intensity comparison, obtained with quantitative and qualitative TTC-based method.

\begin{tabular}{|c|c|c|c|c|c|c|}
\hline \multirow[b]{2}{*}{ Qualitative TTC-based method } & \multicolumn{6}{|c|}{ Quantitative TTC-based metod } \\
\hline & Total & Lack & Weak & Moderate & Strong & Very strong \\
\hline Total & 39 & 3 & 5 & 7 & 10 & 14 \\
\hline Lack & 0 & 0 & 0 & 0 & 0 & 0 \\
\hline Weak & 2 & 0 & 0 & 0 & 2 & 0 \\
\hline Moderate & 12 & 1 & 1 & 2 & 1 & 7 \\
\hline Strong & 25 & 2 & 4 & 5 & 7 & 7 \\
\hline
\end{tabular}

TTC - 2,3,5-triphenyl-tetrazolium chloride.

Table 5 - P. mirabilis strains biofilm forming intensity comparison, obtained with quantitative and qualitative CV-based method.

\begin{tabular}{|c|c|c|c|c|c|c|}
\hline \multirow[b]{2}{*}{ Qualitative CV-based method } & \multicolumn{6}{|c|}{ Quantitative CV-based metod } \\
\hline & Total & Lack & Weak & Moderate & Strong & Very strong \\
\hline Total & 39 & 0 & 3 & 27 & 8 & 1 \\
\hline Lack & 0 & 0 & 0 & 0 & 0 & 0 \\
\hline Weak & 7 & 0 & 0 & 6 & 2 & 1 \\
\hline Moderate & 19 & 0 & 2 & 13 & 4 & 0 \\
\hline Strong & 11 & 0 & 1 & 8 & 2 & 0 \\
\hline
\end{tabular}

CV - crystal violet. 

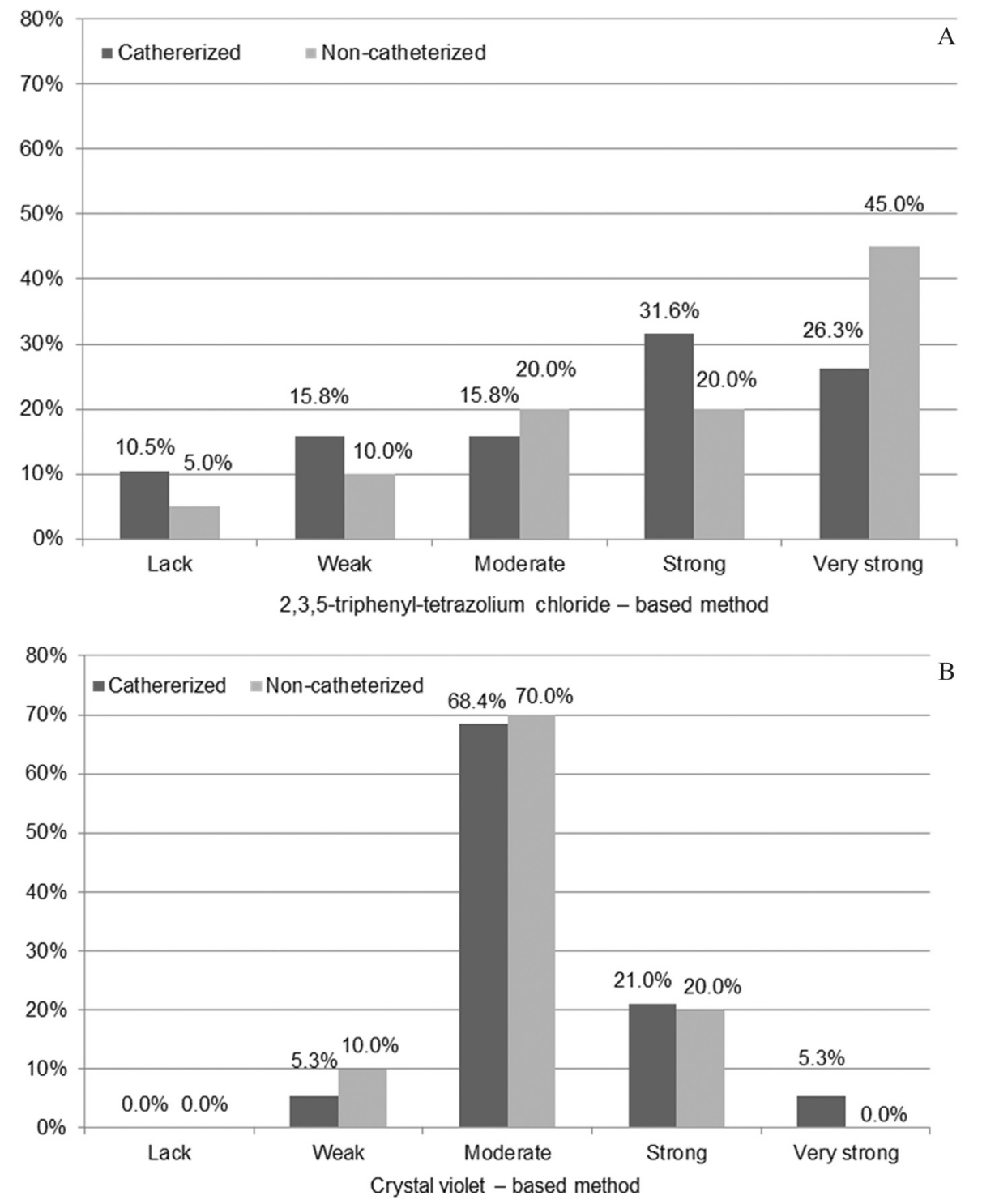

Figure 3 - Comparison of the Proteus mirabilis strains ability to form biofilm with respect to isolation from the urine derived from the catheterized $(\mathrm{n}=19)$ and non-catheterized $(\mathrm{n}=20)$ patients and quantitative method applied.

Salmonella Enteritidis, S. aureus and Listeria monocytogenes bacteria concluded that CV-based method is a quick screening technique with high sensitivity. However, $\mathrm{CV}$ is suitable for biofilm structure size detection but not for its activity estimation. Korenová et al. (2008) evaluated biofilm developed by Pseudomonas aeruginosa, Staphylococcus saprophyticus, $S$. aureus and E. coli strains derived from food processing factories in Slovakia. They recommend $\mathrm{CV}$ application for quantitative biofilm forming estimation, regardless of cells viability due to its ability to stain both, alive and death bacterial cells. It also indicates CV uselessness for biofilm activity evaluation, mentioned in Mahdavi et al. (2007) study. Korenová et al. (2008) results highlighted also CV-based method tendency to overrate biofilm formation level by bacterial strains producing extracellular polysaccharides as a disadvantage but on the other hand advantages of its high reproducibility due to application in many laboratories worldwide, low cost of the dye and rather common instruments for the results read-out. This technique belongs to one of the most popular (Ali, 2012; Balasubramanian et al., 2012; Esteban et al., 2010; Etemadifar and Emtiazi, 2008; Hassan et al., 2011; Khan et al., 2011; Wasfi et al., 2012) and is considered highly optimized. The quantitative method described by Christensen et al. (1985) is believed as gold standard amongst other biofilm detection methods.

On the contrary, quantitative method applying TTC is not so common. Except Mahdavi et al. (2007) it was used by Etemadifar and Emtiazi (2008) work for dehydrogenase 


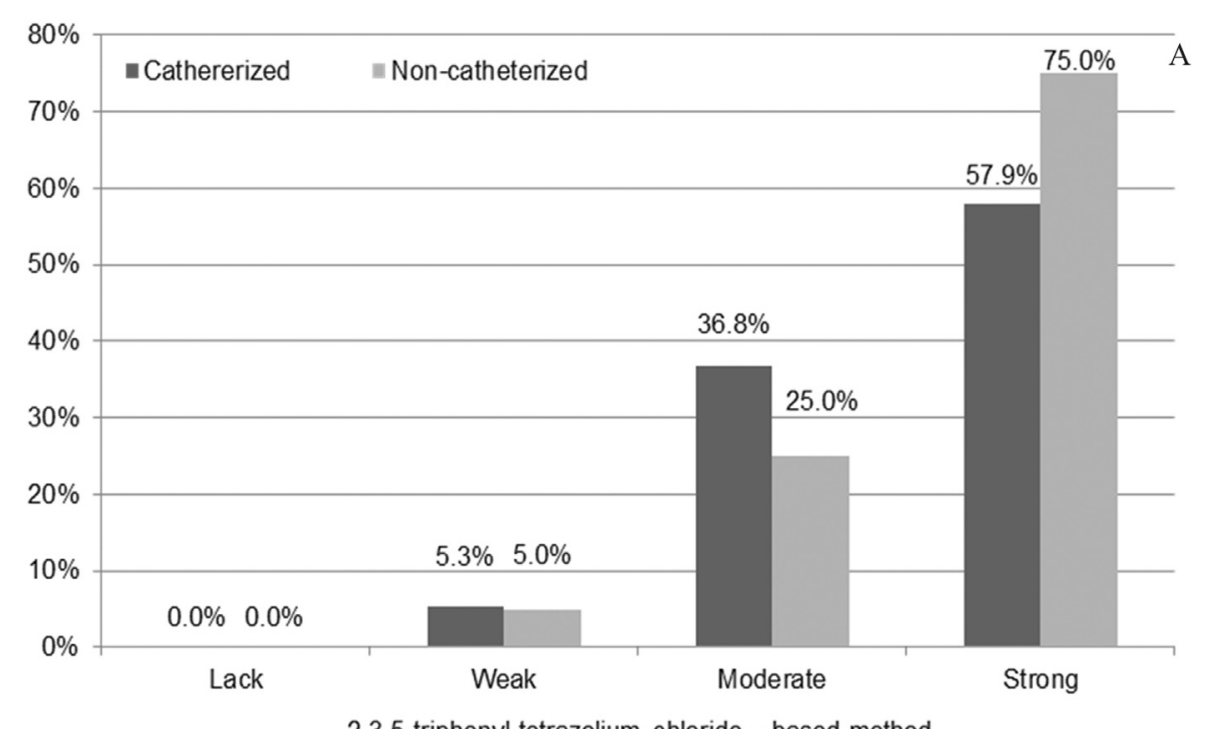

2,3,5-triphenyl-tetrazolium chloride - based method

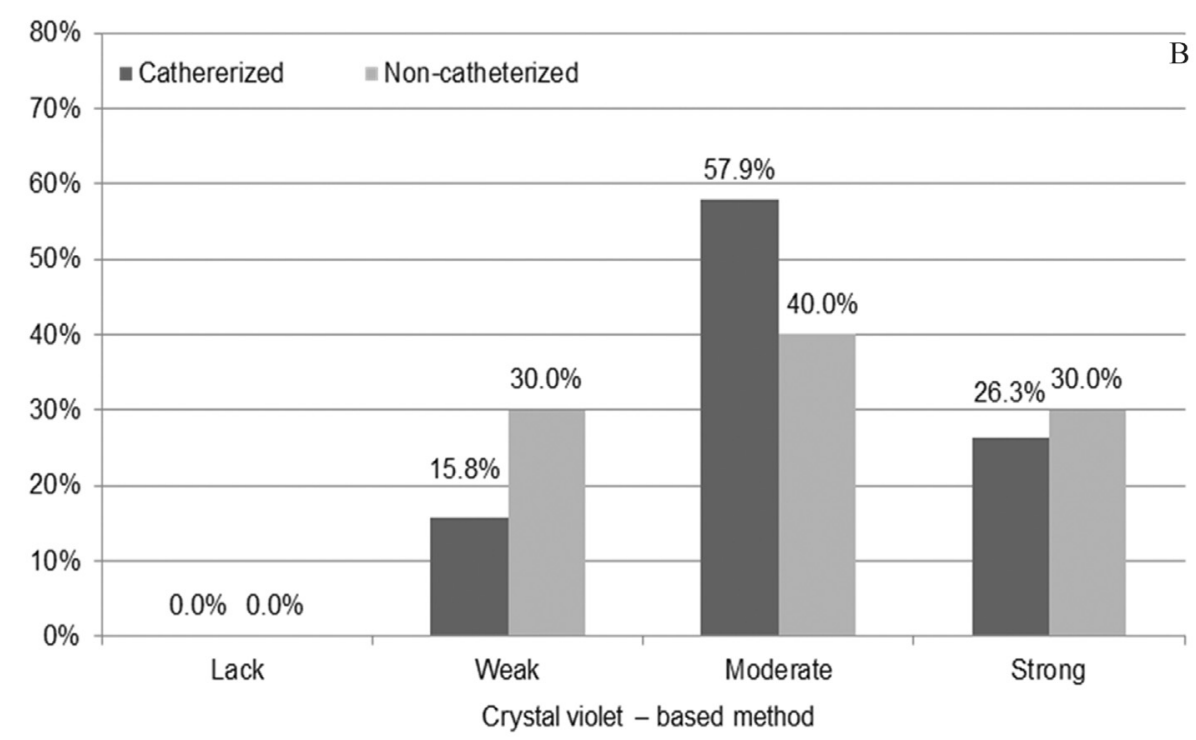

Figure 4 - Comparison of the Proteus mirabilis strains ability to form biofilm with respect to isolation from the urine derived from the catheterized $(\mathrm{n}=19)$ and non-catheterized $(\mathrm{n}=20)$ patients and qualitative method applied.

activity evaluation for Rhodococcus spp. R1 derived from petrol-polluted soil.

Based on the results presented in the current study it is concluded that quantitative CV-based absorbance allows for detection of higher percentage of biofilm-forming strains $(100 \%)$ when compared to TTC-based counterpart $36(92.3 \%)$ strains. The discrepancies observed in biofilm formation intensity in the study presented might be due to differences in procedures applied. In the available literature there is a lack of information on simultaneous evaluation of biofilm formation by the same group of P.mirabilis strains and applying TTC- and CV-based absorbance. In the study presented, additional urine-derived $P$. mirabilis strains ability to form biofilm on the surface of Nelaton catheter fragments was also detected in vitro by applying two simultaneous visual qualitative methods with TTC and CV. The first one was initially introduced by Richards and described and modified by Rózalska et al. (1998). The principles of the method are the colourless TTC dissolution to insoluble formazan by living bacteria and its level evaluation. The red dye intensity on the biomaterial fragments refers to bacterial number and the differences in staining are characteristic for particular strains. Based on that, three levels of TTC reduction were indicated: weak, moderate and strong. All the examined $P$. mirabilis strains displayed ability to form biofilm on the surface of Nelaton catheter, consisting of polyvinyl chloride. Similarly to the results obtained by Rózalska et el. (1998), usefulness of the method was indicated in the current study, mostly due to its technical shortness and high sensitivity. In the Reslinski et al. (2008) study coloured TTC metabolism product was observed quickly, after $40 \mathrm{~min}$ on the surface of surgical mesh while 
in vivo biofilm forming by Staphylococcus spp., Enterococcus spp., Enterobacteriaceae and Pseudomonas aeruginosa strains was detected. Rózalska et al. (1998) highlight that TTC reduction effect appears as shortly as after 1-h incubation and increases with time. Moreover, Reslinski et al. (2010) indicate also sensitivity of TTC reduction-based method, exceeding classic culture methods. It allows for biofilm detection without necessity of its separation from the implant surface and bacteria detection on the biomaterial surface even when the bacteria number is below detectable level when cultured techniques are applied. Rózalska et al. (1998) and Reslinski et al. (2008) studies proved similar metabolism of TTC by the biomaterial-attaching bacterial cells, regardless of biomaterial type, shape and colour. It was also concluded that the formazan accumulation by bacteria does not influence further diagnostic steps. Additional aspect of the method is its doubtless simplicity to perform. Similarly, in the results of the current study none red staining of the sterile biomaterial fragments submerged in TTC-supplemented medium was observed. The results obtained by Rózalska et al. (1998) and Wolska and Jakubczak (2003) as well as results of the study presented confirm the usefulness of the applied method for biofilm formation estimation on the surfaces of biomaterials. According to Reslinski et al. (2010) study results, sensitivity of the visual method applying TTC may decrease number of false negative results in biofilm detection. It was confirmed in the results of the current study. Theability of all examined $P$. mirabilis strains to form biofilm directly on the surface of Nelaton catheter fragments was confirmed. On the contrary to quantitative method with TTC- biofilm formation ability was observed for $92.3 \%$ of the strains tested, and additionally needed for earlier bacterial strains culture. On the other hand, its interpretation depends on visual observation and the possible differences or mistakes result from subjectivity of the researcher. Apart from the studies mentioned above, it was also applied by us in the previous work by KwiecinskaPiróg et al. (2011) and by Bartoszewicz and Secewicz (2008) for biofilm detection on the surface of urinary catheters.

CV-based method for biofilm forming detection with visual interpretation is significantly less common. The results of the present study, confirming ability of all of the examined bacterial strains to form biofilm, are consistent with those obtained when Richards' method was applied. The highest percentage $(48.7 \%)$ of the tested strains was classified as moderate biofilm producers. In the Ali (2012) work biofilm formation by the incrustated urinary cathetersderived $P$. mirabilis strains was evaluated with both, qualitative and quantitative methods with CV. It was concluded that $P$. mirabilis strains display high ability to form biofilm on the urinary catheters as well as in the 96-wells of the polystyrene titter plates (Ali, 2012).
In the study presented, $P$. mirabilis ability to form biofilm in vitro was confirmed for urine isolates derived from catheterized patients as well as physiologically obtained samples. In the Stickler et al. (2006) study of biofilm formation 20 long-term catheterized patients-derived urine samples served as material for bacterial isolation. P. mirabilis rods infection was confirmed for 15 patients. The catheters that the $P$. mirabilis strains were isolated from, displayed incrustation and urine flow blockage. Also other authors (Ali, 2012; Balasubramanian et al., 2012) evaluated in vitro $P$. mirabilis biofilm formation by the strains isolated from the urine of the catheterized patients. In all of them $P$. mirabilis biofilm was observed and accompanied bycatheter incrustation and obstruction.

In the available literature none information on simultaneous studies on detection of biofilm formed by $P$. mirabilis strains derived from non- and catheterized patients has been found. In the study of Abdallah et al. (2011), $43.3 \%$ of the uropathogenic strains of e.g. E. coli, Klebsiella spp., S. aureus and coagulase-negative staphylococci derived from the urine of the catheterized patients displayed ability to form biofilm while for non-catheterized patients' urine-isolated strains e.g. Enterococcus spp. and Pseudomonas spp. the corresponding value was $30 \%$. The comparable results of the biofilm formation were also obtained by Watts et al. (2010) while E. coli isolates derived from non- and catheterized patients urine samples were investigated. In both (Abdallah et al., 2011; Watts et al., 2010) studies mentioned above none statistically significant differences in the obtained results were found in terms of patients catheterization groups. The results of the present study are in concordance with them.

To summarize, $P$. mirabilis strains generally display ability to form biofilm. Its intensity depends on particular strain properties and the accuracy of the detection method applied. Quantitative method with 2,3,5-triphenyl-tetrazolium chloride (TTC) allows for wider discrimination of the strains in terms of biofilm intensity when compared to quantitative crystal violet-based (CV) assay. Applying qualitative method with 2,3,5-triphenyl-tetrazolium chloride (TTC), higher percentage of the examined strains is classified as strong biofilm producers when compared to crystal violet $(\mathrm{CV})$ the assay. Proteus mirabilis strains isolated from the urine derived from non- and catheterized patients form biofilm at the comparable level.

\section{Acknowledgments}

This research was financially supported by the Nicolaus Copernicus University with funds from the maintenance of the research potential of the Department of Microbiology DS-UPB no. 933. 


\section{References}

Abdallah NMA, Elsayed SB, Yassin MM, El-gohary M, Elgohary GM (2011) Biofilm forming bacteria isolated from urinary tract infection relation to catherization and susceptibility to antibiotics. Int J Biotechnol Mol Biol Res 2:172178.

Ali OAU (2012) Prevention of Proteus mirabilis Biofilm by Surfactant Solution. Egypt Acad J of Biol Sci 4:1-8.

Balasubramanian A, Chairman K, Ranjit Singh AJA, Alagumuthu $\mathrm{G}$ (2012) Isolation and identification of microbes from biofilm of urinary catheters and antimicrobial susceptibility evaluation. Asian Pac J Trop Biomed 2:1780-S1783.

Bartoszewicz M, Rygiel A (2006) Biofilm jako podstawowy mechanizm zakazenia miejsca operowanego-metody prewencji w leczeniu miejscowym. Chir Pol 8:171-178.

Bartoszewicz M, Secewicz A (2008) Biofilm w zakazeniach odcewnikowych ukladu moczowego-etiologia i metody prewencji”. Przegl Urol 9:43-45.

Christensen GD, Simpson WA, Younger JA, Baddour LM, Barrett FF, Melton DM, Beachey EH (1985)Adherence of cogulase negative Staphylococi to plastic tissue cultures: a quantitative model for the adherence of Staphylococci to medical devices. Clin Microbiol 22:996-1006.

Czaczyk K, Myszka K (2007) Mechanizmy warunkujace opornosæ biofilmów bakteryjnych na czynniki antymikrobiologiczne. Biotechnologia 76:40-52.

Drzewiecka D, Sidorczyk Z (2005) Charakterystyka gatunku Proteus penneri - warunkowych patogenów czlowieka”. Post Mikrob 44:113-126.

Dubiel G, Dziublewska B, Zaloudik E (2011) Analiza wyników posiewów krwi pacjentów specjalistycznego zespolu chorób pluc i grulicy w Bystrej w latach 2008-2010. Prz Epidemiol 65:447-450

Esteban J, Molina-Manso D, Spiliopoulou I, Cordero-Ampuero J, Fernández-Roblas R, Foka A , Gómez-Barrena E (2010) Biofilm development by clinical isolates of Staphylococcus spp. from retrieved orthopedic prostheses. Acta Orthop 81:674-679.

Etemadifar Z and Emtiazi G (2008) Microtitre plate assay for biofilm formation, production and utilization of hydroxybiphenyl by Rhodococcus sp. isolated from gasolinecontaminated soil. J Biosciences 63:599-604.

Hassan A, Usman J, Kaleem F, Omair M, Khalid A, Iqbal M (2011) Evaluation of different detection methods of biofilm formation in the clinical isolates. Braz J Infect Dis 15:305311.

Hola V, Peroutkova T, Ruzicka F (2012) Virulence factors in Proteus bacteria from biofilm communities of catheterassociated urinary tract infections. FEMS Immunol Med Microbiol 65:343-349.

Jacobsen SM, Shirtliff ME (2011) Proteus mirabilis biofilms and catheter-associated urinary tract infections. Virulence 2:460-465.

Jones SM, Yerly J, Hu Y, Ceri H, Martinuzzi R (2007), Structure of Proteus mirabilis biofilms grown in artificial urine and standard laboratory media. FEMS Microbiol Lett 268:1621.
Khan F, Shukla I, Rizvi M, Mansoor T, Sharma SC (2011), Detection of biofilm formation in Staphylococcus aureus. Does it have a role in treatment of MRSA infections?. Trends Med Res 6:116-123.

Kolwzan B (2011) Analiza zjawiska biofilmu - warunki jego powstawania i funkcjonowania. Ochr Sr 33:3-14.

Korenová J, Lopasovská J, Kuchta T (2008) Comparison of three microtitre plate-based methods for quantification of biofilm formation ability of bacteria contaminating food technologies. J Food Nutr Res 47:100-104.

Kwiecinska-Piróg J, Bogiel T, Gospodarek E (2011) Porównanie dwiema metodami tworzenia biofilmu przez paleczki Proteus mirabilis na powierzchni róznych biomaterialów, Med Dosw 63:131-138.

Liu D (ed.) (2011) Molecular Detection of Human Bacterial Pathogens. CRC Press.

Mahdavi M, Jalali M, Kermanshahi RK (2007) The effect of nisin on biofilm forming foodborne bacteria using microtiter plate method. Res Pharm Sci 2:113-118.

Mobley HLT, Belas R (1995) Swarming and pathogenicity of Proteus mirabilis in the urinary tract. Trends Microbiol 3:280-284.

O’Toole G, Kaplan HB, Kolter R (2000), Biofilm formation as microbial development. Annu Rev Microbiol 54:49-79.

Reslinski A, Mikucka A, Szczesny W, Szmytkowski J, Gospodarek E, Dabrowiecki S (2008) Wykrywanie biofilmu in vivo na powierzchni siatki chirurgicznej. Chir Pol 10:181188.

Reslinski A, Mikucka A, Szmytkowski J, Glowacka K, Szczesny W, Gospodarek E, Dabrowiecki S (2010) Biofilm detection on the surface of hernia mesh implants. Adv Clin Exp Med 19:685-690.

Rózalska B, Sadowska B, Wieckowska M and Rudnicka W (1998) Wykrywanie biofilmu bakteryjnego na biomaterialach medycznych. Med Dosw 50:115-122.

Rózalski A, Kwil I, Torzewska A, Baranowska M and Straczek P (2007), Bakterie z rodzaju Proteus - cechy i czynniki chorobotwórczosci. Post Hig 61:204-219.

Stickler DJ, Jones SM, Adusei GO, Waters MG, Cloete J, Mathur S, Feneley RCL (2006) A clinical assessment of the performance of a sensor to detect crystalline biofilm formation on indwelling bladder catheters. BJU International 98:12441249.

Szewczyk EM (ed) (2006) Diagnostyka bakteriologiczna. Wydawnictwo Naukowe PWN, Warszawa.

Wasfi R, Abd El-Rahman OA, Mansour LE, Hanora AS, Hashem AM, Ashour MS (2012) Antimicrobial activities against biofilm formed by Proteus mirabilis isolates from wound and urinary tract infections. Indian J Med Microbi 30:76-80.

Watts RE, Hancock V, Ong C-LY, Vejborg RM, Mabbett AN, Totsika M, Looke DF, Nimmo GR, Klemm P, Schembri MA (2010) Escherichia coli isolates causing asymptomatic bacteriuria in catherized and noncatherized individuals possess similar virulence properties. J Clin Microbiol 48:24492458.

Wolska K, Jakubczak A (2003) Wykrywanie biofilmu Pseudomonas aeruginosa na biomaterialach medycznych. Med Dosw $55: 371-378$.

All the content of the journal, except where otherwise noted, is licensed under a Creative Commons License CC BY-NC. 